\title{
Design and Implementation of Rural Community Elderly Culture Platform Based on Real-Time Social Media Data Mining
}

\author{
Yangang Zhou' ${ }^{1}$ and Xiao $\mathrm{Hu} \mathbb{D}^{2}$ \\ ${ }^{1}$ School of Fine Arts and Art Design of Kunming University, Kunming City, China 650214 \\ ${ }^{2}$ School of Arts, Wuhan Institute of Technology, Wuhan City, China 430205 \\ Correspondence should be addressed to Xiao Hu; 07091401@wit.edu.cn
}

Received 12 August 2021; Accepted 17 September 2021; Published 26 October 2021

Academic Editor: Rajesh Kaluri

Copyright ( 2021 Yangang Zhou and Xiao Hu. This is an open access article distributed under the Creative Commons Attribution License, which permits unrestricted use, distribution, and reproduction in any medium, provided the original work is properly cited.

\begin{abstract}
In the current big data environment, science and technology not only provide a new governance model for rural community governance but also put forward higher requirements for rural community governance level. Under the background of rural revitalization, promoting the construction of rural community cultural service system is not only an important choice to realize the equalization of urban and rural basic public services but also an important way to protect the cultural rights and interests of rural residents. On the basis of analyzing the real-time data of social media, this paper studies the design and implementation method of rural community culture platform and then puts forward the strategy of community public culture informatization construction under the background of aging. From a global perspective, all countries have their own ways and means to invest in public cultural services. Especially from the perspective of countries with better development of public cultural services, multichannel funding sources are an important indicator of the quality of cultural undertakings. With the development of China's social economy, the rural endowment insurance system is becoming more and more perfect, and the basic living needs of the elderly are basically met.
\end{abstract}

\section{Introduction}

Based on the characteristics of social media digitization and interactivity, the rural community informatization construction mode is being reconstructed, and the new chapter of rural community governance with rural residents as the core and interactive dialogue as the characteristics is slowly opening [1]. The construction of rural community is a systematic project, covering infrastructure, economy, culture, and other dimensions. As an important part of the construction of new socialist countryside, the importance of informatization in rural community construction is self-evident [2]. The development and innovation of community cultural activities are of great significance for the city to build a harmonious society and carry forward the socialist spiritual civilization culture [3]. To strengthen the cultural construction of rural communities, with the support and joint participation of the government and all sectors of society, and in combination with the specific requirements of China's political, eco- nomic, social, and cultural development in the new era, efforts should be made to create a lifestyle based on meeting the material and spiritual needs of the elderly, which is to promote and practice the socialist core values in the new era [4]. It is an important guarantee to enhance the ideological and moral cultivation of citizens and promote the stability, harmony, civilization, and progress of the whole society [5]. Under the background of Rural Revitalization Strategy, it is of great practical significance and academic value for the construction of Chinese cultural undertakings to study the achievements, existing problems, causes and measures of the current construction of Chinese rural community cultural service system, explore the relationship between Chinese excellent traditional culture and public cultural service system, and study the spiritual connotation of Chinese traditional culture [6].

Although compared with urban areas, the Internet penetration rate in rural areas still needs to be improved, and the trend of rapid penetration of the Internet into rural areas 
is irreversible. Especially in recent years, with the rapid development of mobile Internet, social media is quietly approaching rural residents, affecting all aspects of rural life [7]. All these have laid a good foundation for the social media era to open a new chapter of rural community informatization construction. Rural Revitalization Strategy is a major decision-making deployment of the 19th National Congress of the Communist Party of China, a general charter to guide rural work in the new period, and a driving force to realize rural modernization in an all-round way [8]. Under the background of rural revitalization, promoting the construction of rural community cultural service system is not only an important choice to realize the equalization of urban and rural basic public services but also an important path to protect the cultural rights and interests of rural residents [9]. The elderly is an important part of Chinese society, their living conditions are directly related to the level of social development, and their relationship directly affects the degree of social harmony [5]. With the development of China's social economy, the rural endowment insurance system is becoming more and more perfect, and the basic living needs of the elderly have been basically met. But today's elderly are not only satisfied with food and clothing, they are eager for rich and colorful cultural life and have strong spiritual and cultural needs [10]. To do a good job in cultural construction is an important work in the new era. As a complex and huge system engineering, the community culture construction under the aging trend needs the joint participation of all sectors of society to achieve the desired results [11].

Data mining technology is a kind of data processing technology, which is a process of extracting information and knowledge hidden in a large number of incomplete, noisy, fuzzy and random data, which people do not know in advance and are potentially useful. In the context of big data, promoting the informatization of rural communities is an important part of realizing rural "good governance." With the rapid development of the mobile Internet, social media is rapidly infiltrating the vast rural areas, not only integrating into the daily lives of rural residents but also providing a new carrier support for information dissemination in rural communities [12]. The cultural construction of rural communities is the basic project for the construction of spiritual civilization in our country, and it is also an important task for promoting and practicing the core values of socialism in the new era and building a harmonious, civilized, and stable community environment [13]. With the advancement of the rural revitalization strategy, the construction of public cultural services in rural communities in my country still faces many challenges. The insufficient supply of public cultural services has increasingly hindered the steady progress of the rural revitalization strategy. There is an urgent need to vigorously improve the construction of cultural services in rural communities. From the perspective of national strategy, rural culture, especially public culture, plays an increasingly important role in rural construction and development. It has become the key to rural modernization and the foundation of rural stability and harmony. How to create a stable, harmonious, and healthy social and cultural environment is an inevitable requirement for aging and social development, as well as an objective need to fully realize the goal of building socialism with Chinese characteristics [14]. Based on the real-time data analysis of social media, this paper studies the design and implementation method of rural community culture platform under the background of big data and then puts forward the strategy of community public culture informatization construction under the background of aging. The construction of rural community cultural system is helpful to promote the multidimensional coordinated development of rural areas and can promote the economic and social development of rural areas through the cooperation of multiple subjects.

This paper first discusses the relationship between social media big data and the construction of rural community information from three aspects: the construction requirements of rural community information, the business characteristics of knowledge governance, and the influence of population aging on the construction of rural community culture, then analyzes the application significance of big data in the construction of community cultural activities, and then puts forward the construction method of rural community elderly culture platform based on real-time social media data mining, in order to improve the rural community elderly culture and information construction.

\section{The Connection between Social Media Big Data and Rural Community Informatization Construction}

2.1. Requirements for the Construction of Rural Community Information. Social media, also known as social media, is the inevitable product of the development of network media to a certain stage. As a content production and exchange platform based on users' social relations, its basic characteristics are mainly manifested in two aspects, one is the combination of content production and socialization, and the other is that the protagonist of social media platform is users, not website operators [14]. Compared with urban communities, the informationization of rural community management started late, with few people skilled in using computers, lack of professional developers, and few applications of management information systems [15]. A small number of computers and networks are mainly used for simple document processing or low-level entertainment activities such as surfing the Internet and chatting, which are rarely combined with the daily management of the community. Community informatization construction provides a more reliable supporting platform and a good system environment for community service and governance and lays a foundation for the innovation of governance in a smart society. Governance in rural community information is a systematic project, which requires not only the organic division of labor and coordination among various departments but also the sharing and sharing of information [16]. From the current reality, rural community information has limited supply of governance resources and information 
platform, limited space for social and market intervention, difficult to show the advantages of professional services of social organizations, difficult to extend the power of market mechanism to optimize resource allocation, and few opportunities for society and market to provide professional guidance for community governance, which is not conducive to giving full play to its role in resource collection, integration and development.

Generally speaking, rural community information governance breaks the barriers between vertical and horizontal governments, realizes deep cooperation between vertical departments and horizontal departments, breaks the pattern of separation of powers and responsibilities, information monopoly and exclusion, and builds government departments at all levels into an information network community by rebuilding the intranet office system and operation management system. The collaborative governance mechanism of rural community information governance is shown in Figure 1.

Information dissemination in the era of social media not only has the characteristics of "digitalization" and "interactivity" of general online media but also breaks the resource barrier of limited computers in the past. To some extent, as long as rural residents have a smart phone, they can catch up with the fast lane of rural community information construction in the new era. With the development of economy and society, the arrival of an aging society, and the advancement of urbanization, the security function of land is gradually weakened, and the traditional pension mode of relying on children and land is no longer enough to guarantee the elderly life of farmers. Carrying out cultural activities in rural communities can enrich the daily life of the elderly, improve their cultural and moral cultivation, change their inherent unhealthy lifestyle, be willing to communicate with each other, share the fun in life, and actively participate in community cultural entertainment and physical fitness activities [17]. There is a big gap between information governance and residents' needs. With the rapid transformation of rural society, the needs of community residents are increasingly diversified, and the demand for individualization and independence is increasing. However, the rural community information service platform focuses on community residents' convenience services, and localization and expansion services are limited. The construction of rural public service system is not only the concrete result of the overall promotion of rural civilization but also the value channel to meet the subjective needs of rural residents.

\subsection{Analysis of Knowledge Governance and Its Business} Characteristics. With the globalization of economy, common knowledge becomes more and more important as the foundation of global governance. However, the era of big data makes the original knowledge more fragmented and decentralized, which makes it very difficult for subjects to form common knowledge [18]. Common knowledge, as the cornerstone of social group decision-making, is also the premise of common action and common value in group decisionmaking, which greatly affects the judgment and behavior of cognitive subjects. In the process of modernization, informa- tionization has increasingly become an important force to promote rural social change after industrialization, urbanization, and marketization. Information technology has extended into various fields of rural economy and society and promoted the leap forward development of rural economy and society. The diversification of knowledge governance subjects is embodied in the intersubjectivity of multisubjects in rural community public affairs governance, which refers to the relationship between two or more subjects. According to the reality of rural community economic and social development, the national rural strategic planning, the practical interests, and basic concerns of the majority of rural residents, a service function module with multiple functions, various forms and residents' acceptability can be constructed, which can not only ensure the party and state policies to go to the countryside quickly but also ensure the timely feedback of community residents' interests and demands, and realize the timely docking of supply and demand information and the effective supply of services.

\subsection{The Influence of Aging Population on the Construction of} Rural Community Culture. With the profound changes in the social and economic fields, great changes have taken place in the social life fields, which put forward newer and higher requirements for the cultural work, and also put forward new tasks for doing a good job in the cultural work for the elderly. Urban settlement has created wealth and opportunities for society [19]. But with it, the problem of urban population aging has become increasingly prominent. How to create a stable, harmonious, and healthy social and cultural environment, enrich the cultural life of the elderly and meet the spiritual and cultural needs of the elderly is the inevitable requirement of the age and social development of the elderly, and it is also the objective need to fully realize the grand goal of building socialism with Chinese characteristics. With the improvement of material living standards, the demand of the elderly for spiritual and cultural life is getting stronger and stronger. How to meet the growing spiritual and cultural needs of the elderly and enrich the spiritual life of the elderly is of great significance to the realization of family harmony, social harmony, and intergenerational harmony. Through the cultural construction of a certain cultural form and background, the elderly group can naturally form a whole with similar identity points at both psychological and formal levels, which has very important practical significance for the managers of the elderly group. Community is the primary way to solve social problems. Due to the general extension of the life span of the population, the life time of the whole effective labor has been continuously extended, and the overall labor cost in the social economy has decreased; that is, some elderly people have changed from the consumption population to the production population, making due contributions to the creation of social wealth. The analysis framework of cultural platform design in rural community public affairs under big data environment is shown in Figure 2.

Regional culture, as a soft constraint, also plays a vital role in the formation of consensus. The regional culture here is the established system, and the regional cognitive subjects 


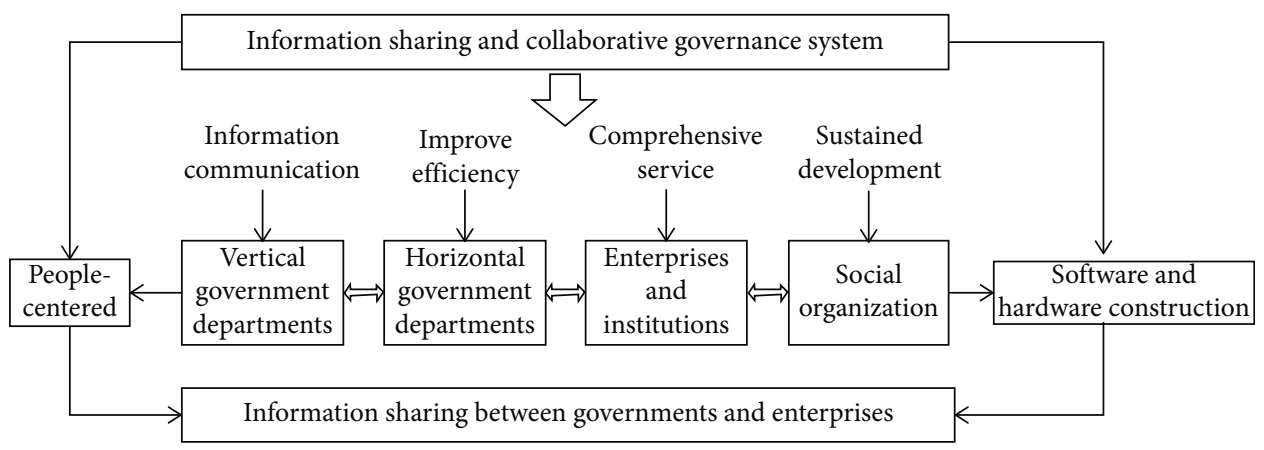

FIGURE 1: Collaborative governance mechanism of community informatization.

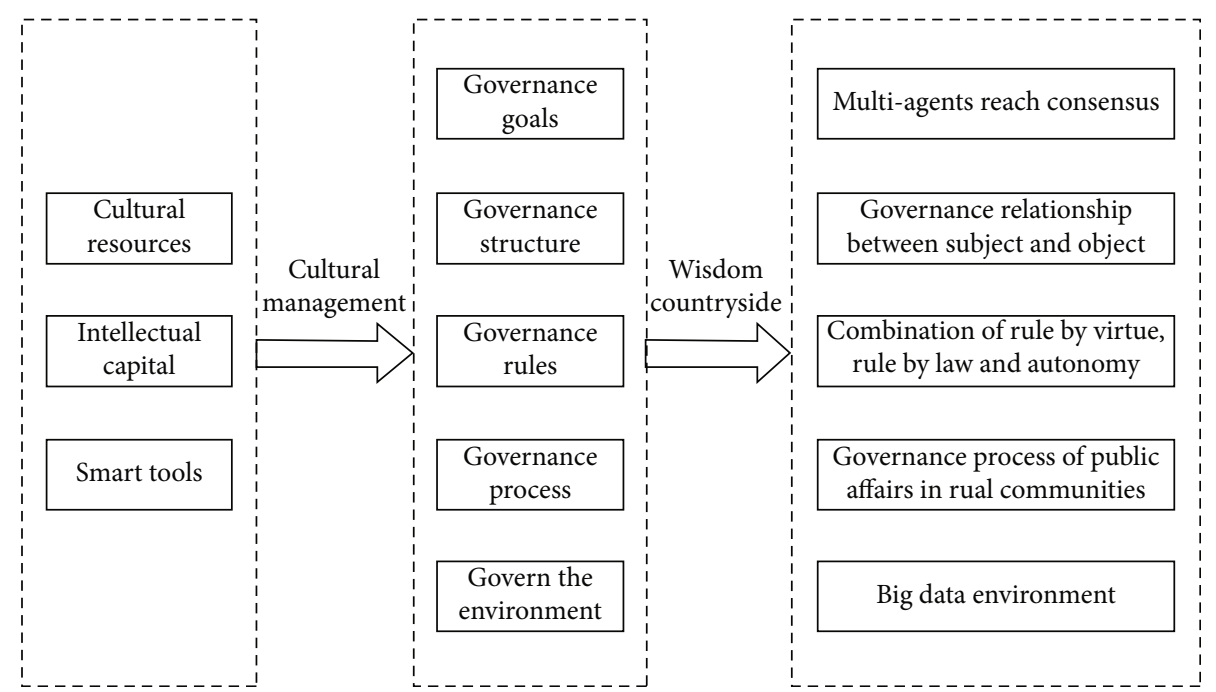

FIGURE 2: Cultural activity management analysis framework.

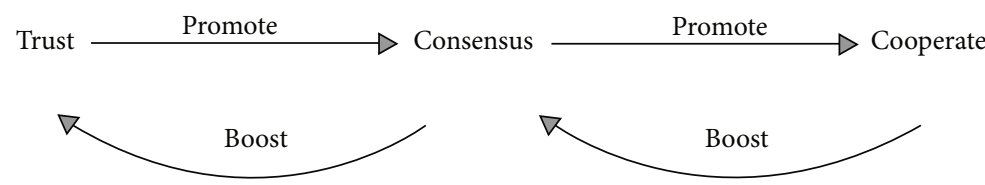

FIgURE 3: The relationship of trust, consensus, and cooperation.

have a strong resonance with the same regional culture, that is, trust; so, it is easier for the subjects to form consensus. The relationship among trust, consensus, and cooperation is shown in Figure 3.

Rural culture is an important continuation of national culture. After thousands of years of precipitation, it has become an important spiritual support for rural economic and social development. Rural culture has the characteristics of the times, which can closely fit with the development of the times and standardize the social order. From the perspective of farmers' needs, we should build a more diversified rural cultural service system and promote the coordinated development of rural community cultural service system with demand value. Actively carrying out cultural activities in rural communities and innovating new cultural service models are not only conducive to the construction of community culture, increasing the cohesion of community groups, but also reducing many burdens for solving the problem of social pension. On the one hand, the old-age culture has gradually become an indispensable part of community culture construction, and the construction of community old-age culture will meet the development requirements of social aging. On the other hand, the aging of the population puts forward higher requirements for the construction of socialist spiritual civilization. The construction of the rural community cultural service system is formed on the basis of rural culture. In the concrete construction process, it also provides public cultural products for the broad masses of rural residents, enriches the amateur cultural life of the broad masses of the people, and at the same time helps to unite the multisubject forces of rural revitalization.

\section{The Role of Big Data in the Construction of Community Cultural Activities}

3.1. Promote Community Cultural Activities to Form Feedback Mechanism. The construction of big data 
environment can effectively understand the needs of multisubjects, collect the interests and needs of multirural community governance subjects for public affairs, and improve the accuracy of cultural activities management content. One of the important parts of the management of cultural activities in rural community public affairs is to collect the needs of various subjects and analyze their needs. Because of the characteristics of villagers' mobility, it is difficult for traditional methods to collect all the needs. Using big data, mobile Internet and other technologies can effectively collect the real needs of villagers. Big data technology can also actively stimulate residents' cultural needs and dynamically collect and analyze residents' cultural needs, so as to determine the specific forms of community cultural activities [20]. This kind of big data model has been used in the commercial field for a long time and is quite successful. We can learn from the successful model in the commercial field to build community culture and deal with residents' cultural needs in a timely and efficient manner. For rural communities, the objects that need to provide management of cultural activities may be villagers, enterprises, and public organizations, and the needs of multiple subjects are often different. If the knowledge services provided are uniform and not targeted, the user experience is often very low, relying on big data technology to provide personalized services, improve the utilization rate of knowledge, and improve the governance level and ability of rural communities by classifying governance objects and providing targeted and accurate services. The construction of big data environment can integrate the fragmentation knowledge of rural communities and improve the accuracy of cultural activity management content.

3.2. Improve the Effective Utilization Rate of Community Cultural Activities Funds. Big data provides data support for the decision-making behavior of public affairs governance in rural communities by collecting a large number of diverse data resources. And through big data means such as data mining, hidden information can be effectively mined to provide data support for scientific decision-making. The era of big data provides the possibility and feasibility for China's rural communities to move towards informationbased governance and finally towards intelligent community governance. The data mining process is shown in Figure 4.

Through real-time social media data mining, residents' cultural needs can be accurately located, and an effective feedback mechanism can be formed, which is conducive to improving the utilization rate of cultural activities resources. It can also provide one-stop community cultural services for community residents, including activities reservation, venue reservation, community settlement, and other functions. Specific to each resident, the activities pushed on the home page may be different. Such accurate push will inevitably enhance the enthusiasm of residents to participate in community cultural activities. The construction of big data environment can effectively play the advantages of multiagents in rural community public affairs governance, achieve a community of interests, coordinate multiagent behavior, and realize the governance pattern of "smart countryside" with multiagent governance.

\section{Construction of Rural Community Elderly Culture Platform Based on Real-Time Social Media Data Mining}

4.1. Strengthen the Mining and Integration of Resources. In order to make the cultural construction achieve better results, we need to strengthen the mining of social resources on the basis of the existing cultural facilities for the elderly, gradually build and improve the cultural construction work, and build the service network of information consultation and help for the elderly. In the rational allocation of resources, we can take the form of individual donation, enterprise sponsorship, and government funding to gradually form a set of perfect cultural construction system. The rural community pension model is flexible, suitable for local conditions to develop pension service system, to meet the different needs of different groups. Different levels of economic development in different regions determine that there are differences in the elderly care services provided by rural communities, and the different living conditions and ideas of the elderly also determine that the elderly care needs are not the same [21]. Providing the necessary platform for the entertainment and self-cultivation of the elderly is the basic guarantee for the development of community elderly culture. It is also an effective way to meet the cultural consumption needs of the elderly and promote the development of community elderly culture. At the same time, it is also the most practical and specific work that community workers should carry out. Before infrastructure construction, we must first communicate with the villagers, understand the accurate needs and requests of the villagers in detail, and then formulate the relevant design and construction scheme. In the construction process, it is necessary to arrange the responsible staff to be present in the whole process, deal with the emergency in time, and ensure that the property of the rural people will not be lost in the construction process.

As shown in Table 1, some women working in the household farm and even some younger and healthy elderly people have clearly indicated that they are willing to join the elderly care service team and show a strong learning enthusiasm.

Under the environment of big data, individuals are both information publishers and information receivers. The development of mobile Internet and big data has strengthened the multiple attributes of cultural activity management, which makes it easy for those who are incapable and lack enthusiasm to participate in expressing their views, and enriches the universality of governance subjects, thus strengthening the multiple attributes of governance. The main body of cultural construction is shown in Figure 5.

The characteristics of the rural community pension model determine that it can formulate the pension service system and provide pension service according to local conditions according to the development of different regions and the living conditions of the elderly, so as to meet the different needs of the elderly. In addition, the providers and service contents of community aged care services are various. This diversified form of community aged care services is also convenient to meet the differentiated needs of the elderly and tailor different service contents for the elderly. In order to cope with the crisis caused by the current rural labor 


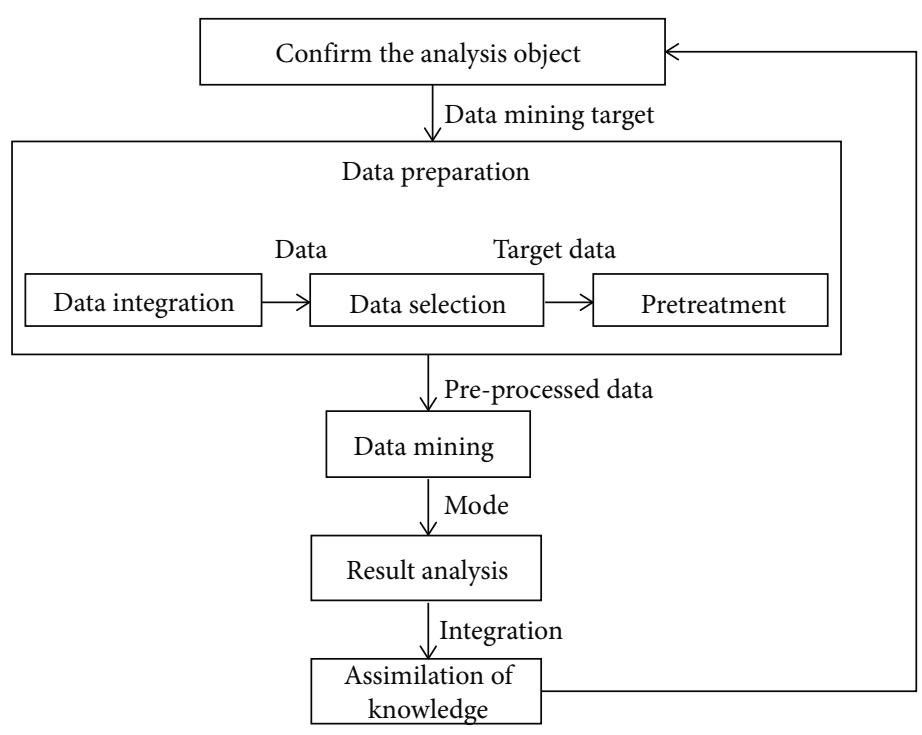

Figure 4: Data mining process.

TABLE 1: Investigation on farmers' wishes.

\begin{tabular}{lccc}
\hline Willingness survey & Willing to join & Unwilling to join & Uncertain \\
\hline Number of people & 35 & 10 & 11 \\
Proportion & $62.5 \%$ & $17.9 \%$ & $19.6 \%$ \\
\hline
\end{tabular}

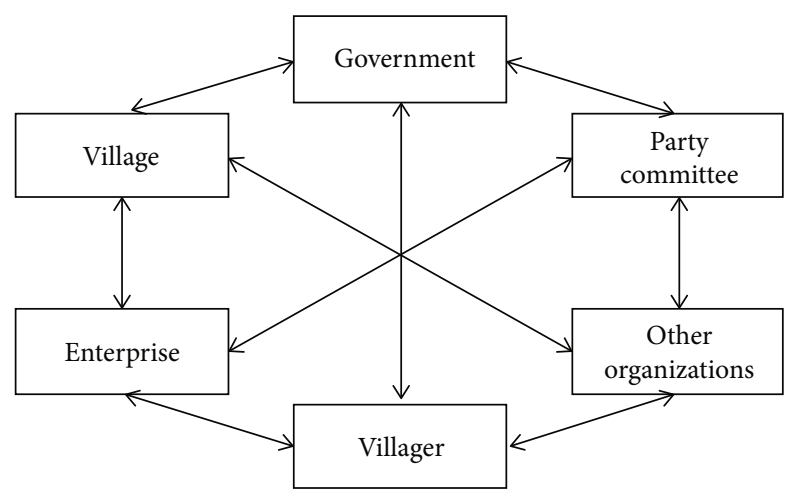

FIgURE 5: The main body of cultural construction.

outflow and promote the sustainable development of rural economy and society, it is necessary to increase the attractiveness of all kinds of talents including cultural talents and strengthen the construction of cultural service talents in rural communities. In the construction of resource sharing mechanism, government agencies at all levels should give full play to the macro guidance role and give strong support in policies. Community neighborhood committees and other institutions can use their own cultural facilities and resources to create better conditions for the cultural activities of the elderly. To develop the model of providing for the aged in rural communities, we only need to make use of the existing resources and appeal to all sectors of society to donate the equipment needed by the elderly.

Community residents can directly express their own interests through the bottom-up social conditions and public opinion feedback system and directly participate in the decision-making of related community affairs and participate in community public governance. The multilevel community resident two-way information transmission and participation governance system are shown in Figure 6.

Get all the items scored by community users $i$ and $j$, then calculate the similarity between them through different similarity measurement methods, and record it as $\operatorname{sim}(i, j)$. This article uses a modified cosine similarity calculation method:

$$
\operatorname{sim}(i, j)=\frac{E_{c \in I_{i, j}}\left(R_{i, c}-\bar{R}\right)\left(R_{j, c}-\bar{R}_{c}\right)}{\sqrt{\sum_{c \in I_{i, j}}\left(R_{i, c}\left(R_{i, c}-\bar{R}_{c}\right)^{2} \times \sum_{c \in I_{i, j}}\left(R_{j, c}-\bar{R}_{c}\right)^{2}\right)}} .
$$

$R_{i, c}$ is the rating of user $i$ on item $c$, and $\bar{R}_{c}$ is the average rating of item $c$. After calculating the similarity between users, for a user $u$, a set of "neighbors" arranged according to the similarity is generated, $N=\left\{U_{1}, U_{2}, \cdots, U_{t}\right\}, 0 \leq t \leq$ $m$, and $u$ does not belong to $N$. From $U_{1}$ to $U_{t}, \operatorname{sim}\left(u, U_{i}\right)$ $(1 \leq i \leq t)$ is arranged in descending order.

When providing public cultural service products, local grass-root governments should not only consider the universal public cultural service demand and the extension of regional focu, but also pay attention to meeting the cultural needs of different groups. Due to the long return period of public cultural service construction, it is limited by the financial sustainability of local governments. Therefore, it is necessary for relevant government departments to make efforts to help the poor with cultural precision, enhance the ability of local governments to effectively build public cultural services, and ensure the optimal allocation of funds and resources. The elderly living alone have many inconveniences and are prone to loneliness and depression, which indicates that the social psychological support of the elderly is also a problem that cannot be ignored in community 


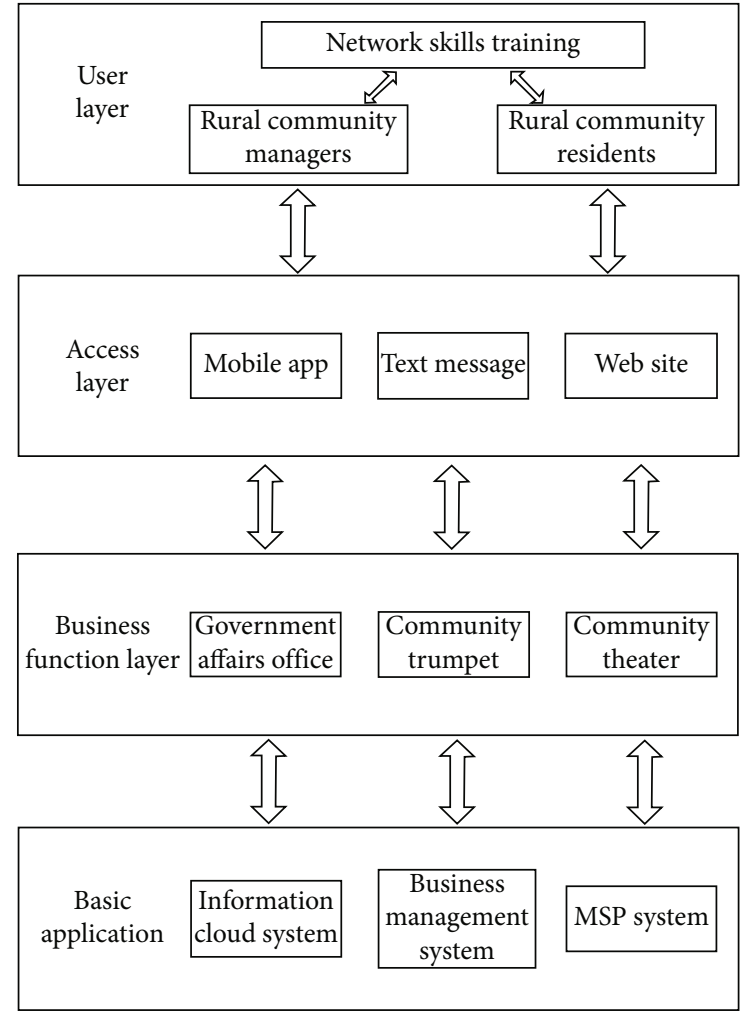

FIgURE 6: Two-way information transmission and governance system for community residents.

nursing services. The prevalence of elderly living alone in community was investigated, and the results are shown in Table 2.

Chronic diseases are the most common diseases that affect the health of the elderly, which may lead to a decline in the mobility of the elderly. The ranking and prevalence of chronic diseases of the elderly are shown in Table 3.

To construct rural community public cultural service with regional and national characteristics is to establish the key development direction according to the advantages of rural historical and cultural resources in different regions and to integrate urban cultural consumption and creative design elements into rural traditional culture to form a new brand of rural community public cultural service. Therefore, we can give full play to the cultural productivity in rural areas, make up for the imbalance between supply and demand of cultural service products in rural communities, and effectively play its cultural and economic functions while protecting traditional local culture. For rural residents, they are direct participants and beneficiaries of the old-age care model in rural communities. The most important thing to develop the old-age model in rural communities is to break the old-age concept of "raising children and preventing old age" in farmers' psychology for a long time and establish the old-age awareness of mutual assistance and mutual aid. Community workers should strengthen the guidance and management of cultural and sports activities for the elderly, take the community as the place and the residents as the main body, and carry out a series of interesting,
TABLE 2: The prevalence of elderly people living alone in the community.

\begin{tabular}{lcc}
\hline Number of disease types & Number of cases & Proportion (\%) \\
\hline 0 & 158 & 25.56 \\
1 & 264 & 42.6 \\
2 & 119 & 19.2 \\
3 & 52 & 8.4 \\
More than three kinds & 27 & 4.4 \\
\hline
\end{tabular}

TABLE 3: The order and prevalence of chronic diseases in the elderly.

\begin{tabular}{lc}
\hline Disease name & Prevalence rate (\%) \\
\hline Hypertension & 30.05 \\
Diabetes & 7.76 \\
Ischemic heart disease & 7.54 \\
Cerebrovascular disease & 6.01 \\
Rheumatoid arthritis & 2.35 \\
Herniated disk & 1.68 \\
Cataract & 1.23 \\
Benign prostatic hyperplasia & 0.95 \\
\hline
\end{tabular}

connotative, competitive, cooperative, and distinctive cultural and sports activities from time to time [22]. We should encourage more community residents volunteers to join the community cultural construction team, especially those who have artistic hobbies and stylistic expertise and are enthusiastic about community affairs, give full play to their leading role, organize the establishment of community cultural activity groups in various forms, and cultivate more elderly residents to become literary lovers and literary backbones, forming a linkage effect [23]. Cultural departments at all levels should actively carry out high-quality cultural activities in conjunction with aging departments, workers, youth, women, and other mass organizations, Federation of Literary and Art Circles associations and social and cultural organizations according to their respective work characteristics. We should encourage all sectors of society to care for and support cultural activities and vigorously advocate and organize volunteer teams to provide various services including spiritual comfort and cultural life for the elderly.

As shown in Table 4, 76\% of rural residents think that they will rely on their children to support the elderly in the future, and they think that their old age life should be taken care of by their children.

A survey on whether farmers are willing to accept the old-age model in rural communities is shown in Table 5. The way of providing for the aged in rural communities can not only ensure that the elderly do not leave their familiar living environment as much as possible, so that they can live with their neighbors, friends and family, but also receive the aged care services provided by the community.

Under the current situation, a large part of rural community pension services need community members to help each other directly. That is to say, if residents and neighbors cannot form a good atmosphere of mutual help and mutual 
TABLE 4: Choices of farmers' pension methods.

\begin{tabular}{lccc}
\hline $\begin{array}{l}\text { Ways of providing for the } \\
\text { aged }\end{array}$ & $\begin{array}{c}\text { Family } \\
\text { pension }\end{array}$ & $\begin{array}{c}\text { New rural } \\
\text { insurance }\end{array}$ & Other \\
\hline Number of people & 41 & 8 & 11 \\
Proportion & $69.5 \%$ & 13.6 & 18.6 \\
\hline
\end{tabular}

TABLE 5: Investigation on the willingness of the community pension model.

\begin{tabular}{lccc}
\hline Willingness survey & Receptibility & Unacceptable & Uncertainty \\
\hline Number of people & 38 & 5 & 13 \\
Proportion & $67.9 \%$ & 8.9 & 23.2 \\
\hline
\end{tabular}

support for the elderly, the development of rural community pension model cannot be discussed. Only when the rural people understand the national policy can they consciously exert their sense of ownership and actively exert their supervision. At the same time, rural people can learn the spirit of national policy documents through this platform, change their ideas, broaden their horizons, and improve their overall quality [24].

\subsection{Promote the Organic Combination of Cultural} Construction and Cultural Industry for the Elderly. To carry out cultural activities, we should start from the needs and aspirations of the elderly and combine the characteristics of different places. Relevant departments must adhere to the community-based, grassroot-oriented, and practical. For public cultural places such as exhibition halls, the elderly can be given appropriate preferential treatment or even free of charge. On the occasion of major traditional festivals every year, giving priority to arranging condolence performances for the elderly has gradually become a system and mobilizes the participation consciousness of the villagers. Villagers are not only the beneficiaries of rural community cultural services but also important participants [25]. Community-based old-age care is a kind of old-age care way based on family-based old-age care, taking the community as the platform, taking the relevant service organizations in the community as the leading force, effectively mobilizing and integrating various resources, and providing all-round and multilevel old-age care services for the elderly. The basic structure of the community pension system is shown in Figure 7.

In order to coordinate various actors with different interests, it is necessary to apply various governance methods, that is, to coordinate the needs and interests of multiple subjects through a series of formal and informal institutional arrangements to realize collective action. Traditional governance rules include bureaucratic governance rules, market governance rules, and network governance rules. Bureaucratic governance rules are based on power relations, and its governance structure is from top to bottom. In the current big data environment, human resources, intellectual capital, social capital, knowledge, and other resources are scattered and fragmented. It is difficult for a single subject

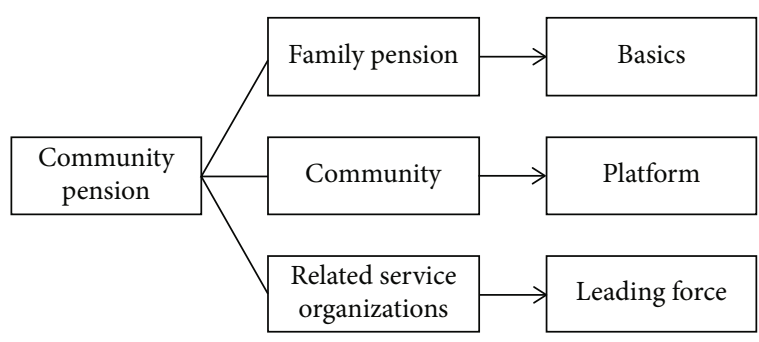

Figure 7: The basic structure of the community pension system.

to achieve its goal by relying on a certain resource. It is necessary to integrate the resources scattered in the hands of multiple subjects to achieve collective action. Market governance rules are based on the economic principle of interaction between consumers and product suppliers, which is the coordination of an exchange system constructed by a rational economic man through "invisible hand." Network governance rules are based on the basic principle of trust to allocate public goods resources. The advantages and disadvantages of bureaucratic governance, market governance, and network governance rules are shown in Table 6.

With the rapid development of society, rural people are paying more and more attention to personal health. It is necessary to strengthen the leadership of cultural work for the elderly, strengthen the research, guidance and management of cultural activities, and ensure the healthy and orderly development of cultural undertakings for the elderly. We should adhere to materialist dialectical thought and correct orientation, actively guide the elderly to carry out various healthy, beneficial and scientific cultural and fitness activities, and oppose various activities that are not conducive to the physical and mental health of the elderly and superstition and pseudoscience. By building a place for mass activities in rural areas, let the people have places and equipment for activities together, let the masses organize activities spontaneously, and enhance the cohesion in rural areas [22]. By strengthening physical exercise, the rural people can strengthen their physical fitness, relieve their fatigue, and benefit their physical and mental health. By organizing activities, the rural people's spiritual and cultural needs were met, and the socialist core values were also educated. Within the statutory authority, the relevant departments of local governments should formulate rules and regulations with legal effect and relevant standards of public cultural services according to the actual situation of the development of public cultural services in the region. The management process of the elderly culture of the two committees in rural community governance under the big data environment is shown in Figure 8.

Rural cultural management workers actively organize and guide rural people to carry out activities they are willing to carry out, and at the same time, embody socialist core values in the process of activities. Perfecting the multichannel funds for rural community cultural construction is an important link to ensure the steady advancement of rural 
TABLE 6: Comparison of advantages and disadvantages of traditional governance rules in rural communities.

\begin{tabular}{lcc}
\hline Governance rules & Advantage & Disadvantage \\
\hline $\begin{array}{l}\text { Bureaucratic } \\
\text { governance }\end{array}$ & Centralization and strong control & The system is rigid and inefficient \\
Market governance & Market regulates resource allocation and pays attention to & Market failures such as insufficient supply of public \\
Network governance & effiency & goods
\end{tabular}

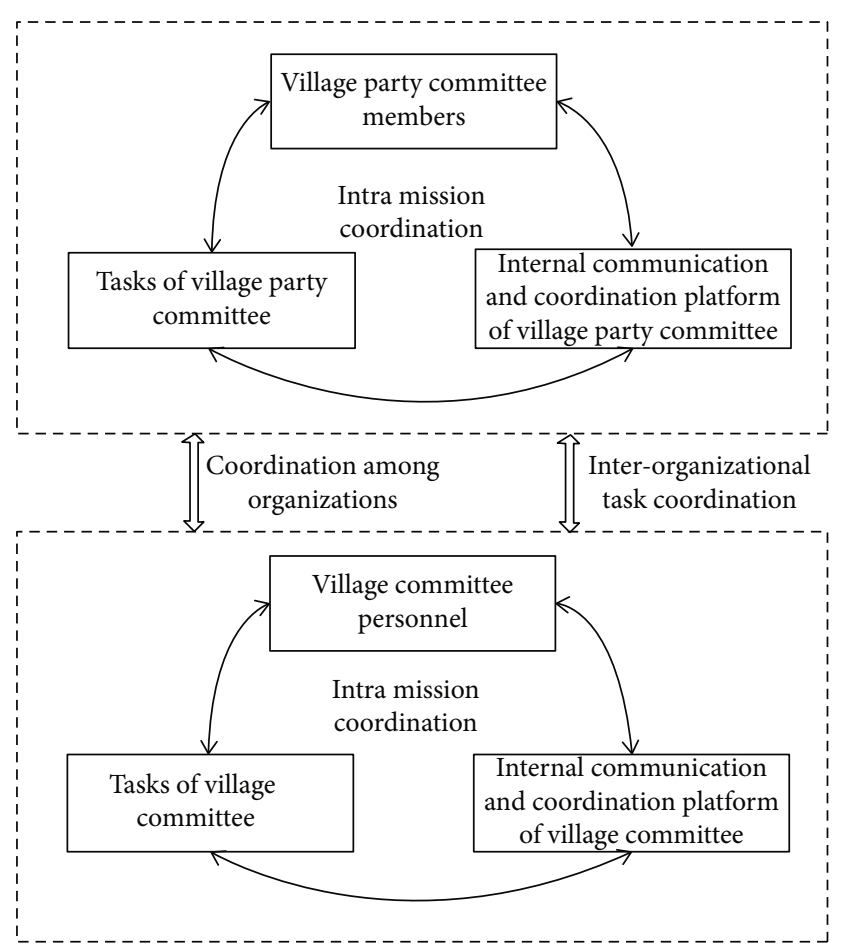

FIGURE 8: The management process of the elderly culture in the village committees.

cultural undertakings. The general situation and physiological functions of the respondents were analyzed by single factor, and the results of stepwise regression analysis are shown in Table 7.

Suppose the expected output is $z_{k}^{\prime}$, and the global error between expected and actual output is defined as $L$ :

$$
L=\frac{1}{2} \sum_{k=1}^{m}\left(z_{k}-z_{k}^{\prime}\right)^{2}
$$

Through the back propagation process, the error is expanded to the hidden layer as

$$
L=\frac{1}{2} \sum_{k=1}^{m}\left[f\left(\lambda_{k}\right)-z_{k}^{\prime}\right]^{2}=\frac{1}{2} \sum_{k=1}^{m}\left[f\left(\sum_{k=1}^{t} w_{j k} y_{j}+b_{k}\right)-z_{k}^{\prime}\right]^{2} .
$$

TABLE 7: Stepwise regression analysis of general conditions and physiological functions.

\begin{tabular}{lccc}
\hline Variable & $\begin{array}{c}\text { Partial } \\
\text { regression } \\
\text { coefficient }\end{array}$ & $\begin{array}{c}\text { Standardized partial } \\
\text { regression coefficient }\end{array}$ & $\begin{array}{c}\text { Standard } \\
\text { error }\end{array}$ \\
\hline $\begin{array}{l}\text { Self care } \\
\text { ability }\end{array}$ & -14.37 & -0.32 & 2.51 \\
$\begin{array}{l}\text { Perplexing } \\
\text { problems } \\
\begin{array}{l}\text { Medical } \\
\text { expenses }\end{array}\end{array}$ & -2.87 & -0.15 & 0.78 \\
$\begin{array}{l}\text { Nursing } \\
\text { needs }\end{array}$ & -6.51 & -0.28 & 1.23 \\
\hline
\end{tabular}

Finally, the reverse transmission to the input layer is

$$
\begin{aligned}
L & =\frac{1}{2} \sum_{k=1}^{m}\left[f\left(\sum_{k=1}^{t} w_{j k} y_{j}+b_{k}\right)-z_{k}^{\prime}\right]^{2} \\
& =\frac{1}{2} \sum_{k=1}^{m}\left[f\left(\sum_{k=1}^{t} w_{j k}\left(\sum_{j=1}^{n} w_{i j} a_{i}+b_{j}\right)+b_{k}\right)-z_{k}^{\prime}\right]^{2} .
\end{aligned}
$$

The network error is a function of the weights $w_{i j}$ and $w_{j k}$. Therefore, the error $E$ can be changed by changing the weight of the neuron; thus,

$$
\begin{gathered}
\Delta w_{i j}=-\varepsilon \frac{\partial L}{\partial w_{i j}}(i=1 \cdots m, j=1 \cdots n), \\
\Delta w_{j k}=-\varepsilon \frac{\partial L}{\partial w_{j k}}(j=1 \cdots n, k=1 \cdots t) .
\end{gathered}
$$

Among them, $\varepsilon$ represents the rate, and $\varepsilon(0,1)$.

From the world point of view, countries have their own ways and means to invest in public cultural services, especially from the perspective of countries with better development of public cultural services, and multichannel funding sources are an important indicator of the quality of cultural undertakings. Rural cultural workers should work hard, make full use of the existing material conditions, realize the "sharing" of rural community cultural service system infrastructure, give full play to the role of infrastructure, meet the spiritual and cultural needs of rural people, and also carry out the education of socialist core values [26]. 
4.3. Development Proposal. Chinese rural people have lived in the environment of local traditional culture for generations, forming the rural life regulations and ethical management with Chinese traditional rural characteristics and maintaining the social stability of Chinese rural areas. The purpose of realizing the rural revitalization strategy is to meet the spiritual and cultural needs of the people in rural areas of China, and it is necessary to protect the diversity of Chinese regional culture. On the basis of understanding people's real needs through various investigation methods, the villagers should be guided to actively participate in the construction of public cultural services in rural communities, so as to stably promote the sustainable operation of the construction. Theoretically speaking, we should pay attention to the continuous study of relevant laws and regulations, mold our own cultural legal literacy, and firmly establish the legal concept of equalization of public cultural services. The construction of community culture can promote Chinese excellent traditional culture, and at the same time, it can continuously improve the moral cultivation, political consciousness, and cultural accomplishment of community residents and then enhance their cultural self-confidence and consciously practice the socialist core values. Only when the rural people have a good health can they live and work in peace and contentment. It is also part of the rural revitalization strategy to build a public activity place so that rural people can move freely.

As a basic work of revitalizing rural culture and promoting rural revitalization in China, while following the task requirements of implementing the rural revitalization strategy and adhering to the socialist core values as the guide, we should take meeting the public cultural needs of farmers as the starting point and strengthen the specific path of working coordination among governments at all levels and relevant departments [27]. As far as the activity places for the elderly are concerned, the existing village branches, rural school buildings, and even some abandoned houses can be used for activities in rural areas. In the process of infrastructure construction, make clear the responsibilities of each post, so as to ensure that the process is supervised, the actions are disciplined, and the results are fed back. At the same time, the acceptance of the project should realize the lifelong responsibility system, ensure that the public cultural service construction funds are used in the cutting edge, and form a high-pressure situation in the system. The community should actively carry out the construction of cultural and sports organizations for the elderly and cultivate a number of elderly cultural and sports backbone teams by relying on regional elderly activity centers and cultural centers to promote the development of grassroots elderly cultural and sports activities. Actively introducing market mechanism and realizing the economic value of old-age culture in the way of market mechanism operation can effectively solve the dilemma of lack of funds, and also help to provide a steady stream of manpower and material resources for the development of old-age culture.

\section{Conclusions}

With the increasing popularity of rural Internet, social media is helping to open a new chapter in the development of rural community information. Under the background of aging population, the construction of rural community culture is conducive to the formation of harmonious, harmonious, and peaceful community atmosphere. Based on the real-time data analysis of social media, this paper studies the design and implementation method of rural community culture platform under the background of big data and then puts forward the strategy of community public culture informatization construction under the background of aging. In a good community humanistic environment, neighbors watch each other, respect each other, and love each other, which effectively alleviates the widespread insecurity and depression of modern people and enables the elderly to live a truly quality old age. Rural villagers are beneficiaries and builders of the construction of the rural community cultural service system. Governments at all levels should adhere to the people-centered working principle, let rural villagers participate in the whole process of building the rural community cultural service system, and give full play to their subjective initiative.

The research on the management of cultural activities in rural community public affairs under the big data environment plays an important role in promoting the modernization of rural community governance level and governance capacity. In the future, the community should actively carry out the construction of cultural and sports organizations for the elderly, rely on regional activity centers and cultural centers for the elderly, cultivate a number of backbone teams of cultural and sports for the elderly, and promote the development of cultural and sports activities for the elderly at the grass-root level.

\section{Data Availability}

The data used to support the findings of this study are included within the article.

\section{Conflicts of Interest}

The authors declare that they have no competing interest.

\section{References}

[1] M. Shade, J. Boron, N. Manley, K. Kupzyk, and C. Pullen, "Ease of use and usefulness of medication reminder apps among rural aging adults," Journal of Community Health Nursing, vol. 36, no. 3, pp. 105-114, 2019.

[2] B. Elizalde-San Miguel and V. Díaz-Gandasegui, "Aging in rural areas of Spain: the influence of demography on care strategies," History of the Family, vol. 21, no. 2, pp. 214-230, 2016.

[3] H. Yangyang, "Social reconstruction mode of left-behind elderly under the deconstruction of Rural Society in Aggregated Nursing Homes," Journal of Sichuan University of Science \& Technology (Social Science Edition), vol. 31, no. 4, pp. 58-67, 2016. 
[4] L. Gongping and F. Fang, "Practice and research on health education for the elderly in township communities under the background of rural revitalization strategy," China Rural Education, vol. 287, no. 1, pp. 42-44, 2019.

[5] H. Wang, "The aging of rural population and the evolution of rural space," Population Research, vol. 43, no. 5, pp. 66-80, 2019.

[6] T. Guojiang, "Experiments and reflections on elderly education carried out by rural community education centers," China Rural Education, vol. 285, no. 23, pp. 50-51, 2018.

[7] G. Yaqiao, J. Ma, J. Wang, and Q. Yang, "The lack of humanistic feelings in the countryside and its reasons," Housing and real estate, vol. 492, no. 7, pp. 282-290, 2018.

[8] L. Liao and X. Gao, "Research progress and prospects of the impact of population aging on rural development," Advances in Geographical Sciences, vol. 37, no. 5, pp. 617-626, 2018.

[9] Z. Mengna, "Research on the design of suitable aging of rural environmental landscape under the background of aging," Art Technology, vol. 32, no. 10, pp. 183-184, 2019.

[10] H. Pan, "Opportunities, challenges and countermeasures for rural revitalization caused by the aging of migrant workers," China economic and trade guide, vol. 949, no. 20, pp. 57-79, 2019.

[11] F. Xiao, J. Tan, L. Zhaojun, and S. Jinyun, “The enlightenment of Taomi Village community construction on the activation of rural cultural heritage," Urban Architecture, vol. 16, no. 2, pp. 85-87, 2019.

[12] X. Deng and H. Jianyun, "Rural community planning methods and practices from the perspective of cultural guidance," The Planner, vol. 35, no. 23, pp. 40-46, 2019.

[13] P. Xiaowen and W. Junying, "The impact of rural population aging on rural revitalization strategy," Cooperative Economy and Technology, vol. 597, no. 22, pp. 13-15, 2018.

[14] H. Shuo, "'aging of farmers" under the strategy of rural revitalization and its countermeasures," Shanxi Agricultural Economics, vol. 270, no. 6, pp. 78-79, 2020.

[15] G. T. Reddy, M. P. K. Reddy, K. Lakshmanna et al., “Analysis of dimensionality reduction techniques on big dat," IEEE Access, vol. 8, pp. 54776-54788, 2020.

[16] Q. Wu, L. Tongtong, Q. Jianling, L. Yingchun, and Z. Runyun, "Research on rural community pension model under the background of rural revitalization strategy," Anhui agricultural Science Bulletin, vol. 399, no. 17, pp. 13-44, 2020.

[17] N. Deepa, Q.-V. Pham, D. C. Nguyen et al., “A survey on blockchain for big data: Approaches, opportunities, and future directions," 2020, http://arxiv.org/abs/2009.00858.

[18] W. Xu and W. Wang, "Research on the integration of rural hollow governance and community construction under the background of rural revitalization strategy," Journal of Agricultural and Forestry Economic Management, vol. 18, no. 3, pp. 416-423, 2019.

[19] Q. Feng and Z. Guanghua, "Thoughts on the development model of rural ecological communities under the background of beautiful rural construction," Science \& Technology Economic Guide, vol. 639, no. 13, pp. 88-89, 2018.

[20] F. Qiong and Q. Wu, "The reconstruction of traditional etiquette culture in the rural revitalization strategy," Chongqing Social Sciences, vol. 287, no. 10, pp. 33-41, 2018.

[21] Y. Guo, Z. Yang, and H. Yue, "The spatiotemporal evolution of the aging of rural population in China and rural revitalization strategies," Geographical Research, vol. 38, no. 3, pp. 667-683, 2019.

[22] Y. Zaiting, "The changes, predicaments and choices of rural culture from the perspective of modernity," Journal of Beijing Institute of Graphic Communication, vol. 25, no. 8, pp. 5155, 2017.

[23] C. Ye, X. Wang, C. Zheng, Y. Ji, and Y. Xie, "Research on the issue of elderly care for the elderly in empty nest in the new situation," Rural Science \& Technology, vol. 252, no. 12, pp. 3334, 2020.

[24] C. Ge and S. Shangeng, "Research on the suitable ageing reformation of rural living environment in urban suburbs," Rural Science \& Technology, vol. 207, no. 3, pp. 16-18, 2019.

[25] Y. Hu, "The predicament and solution of rural cultural construction under the background of rural revitalization strategy," Rural Economy and Technology, vol. 30, no. 11, pp. 247-248, 2019.

[26] H. Wang, H. Lu, F. Zhang, A. Zhang, J. Guo, and J. Dong, "Pursuing a better eating life: a new concept of building shared restaurants in rural communities," Society and Public Welfare, vol. 2020, no. 1, pp. 58-61, 2020.

[27] P. Ying, "Discussion on rural revitalization strategy and intangible cultural heritage protection," Shanghai Urban Management, vol. 27, no. 4, pp. 8-13, 2018. 